Article

\title{
Efficient Removal of Cr(VI) from Water by Biochar and Activated Carbon Prepared through Hydrothermal Carbonization and Pyrolysis: Adsorption-Coupled Reduction Mechanism
}

\author{
Anh Tuan Vo ${ }^{1}$, Van Phuong Nguyen ${ }^{2}$, Abdelkader Ouakouak ${ }^{3}$, Aileen Nieva ${ }^{4}$, \\ Bonifacio T. Doma Jr. ${ }^{4}$, Hai Nguyen Tran ${ }^{5, *(D)}$ and Huan-Ping Chao ${ }^{6, *}$ \\ 1 Faculty of Urban Infrastructure Engineering, University of Architecture Ho Chi Minh City, Ho Chi Minh City \\ 700000, Vietnam; tuan.voanh@uah.edu.vn \\ 2 Center of Excellence for Green Energy and Environmental Nanomaterials, Nguyen Tat Thanh University, \\ Ho Chi Minh City 755414, Vietnam; ngphvan@gmail.com \\ 3 Hydraulic and Civil Engineering Department, University of El Oued, PO Box 789, El Oued 39000, Algeria; \\ ouakouakk@yahoo.fr \\ 4 Mapua University Muralla St. Intramuros, Manila 1002, Philippines; adnieva@mapua.edu.ph (A.N.); \\ btdoma@mapua.edu.ph (B.T.D.J.) \\ 5 Institute of Fundamental and Applied Sciences, Duy Tan University, Ho Chi Minh City 700000, Vietnam \\ 6 Department of Environmental Engineering, Chung Yuan Christian University, Taoyuan 32023, Taiwan \\ * Correspondence: trannguyenhai@duytan.edu.vn (H.N.T.); hpchao@cycu.edu.tw (H.-P.C.); \\ Tel.: +84-0967-070-062 (H.N.T.); +886-3-2654914 (H.-P.C.)
}

Received: 21 May 2019; Accepted: 31 May 2019; Published: 3 June 2019

check for updates

\begin{abstract}
Three carbonaceous porous materials (biochar and activated carbon) were developed from the Tectona grandis tree sawdust. The applied process of two-stage preparation included pre-treatment through hydrothermal carbonization at $190{ }^{\circ} \mathrm{C}$ and subsequent pyrolysis at $800{ }^{\circ} \mathrm{C}$. Two chemical activating agents $\left(\mathrm{K}_{2} \mathrm{CO}_{3}\right.$ and $\left.\mathrm{ZnCl}_{2}\right)$ were used to prepared activated carbons $\left(\mathrm{K}_{2} \mathrm{CO}_{3}-\mathrm{AC}\right.$ and $\mathrm{ZnCl}_{2}-\mathrm{AC}$ ), respectively. They were characterized by textural property, morphology, and surface element components and applied to remove $\mathrm{Cr}(\mathrm{VI})$ from solution at various solution $\mathrm{pH}$ values and initial $\mathrm{Cr}(\mathrm{VI})$ concentrations. Results showed that the textural parameters $\left(S_{\mathrm{BET}}\right.$ and $\left.V_{\text {Total }}\right)$ of the prepared material were $1757 \mathrm{~m}^{2} / \mathrm{g}$ and $1.027 \mathrm{~cm}^{3} / \mathrm{g}$ for $\mathrm{Zn}-\mathrm{Cl}_{2}-\mathrm{AC}, 1013 \mathrm{~m}^{2} / \mathrm{g}$ and $0.418 \mathrm{~cm}^{3} / \mathrm{g}$ for $\mathrm{K}_{2} \mathrm{CO}_{3}-\mathrm{AC}$, and $792 \mathrm{~m}^{2} / \mathrm{g}$ and $0.345 \mathrm{~cm}^{3} / \mathrm{g}$ for biochar. The adsorption process reached the highest efficiency at $\mathrm{pH}$ 3.0. The Langmuir maximum adsorption capacity indicated the decreasing order: $\mathrm{ZnCl}_{2}-\mathrm{AC}(127 \mathrm{mg} / \mathrm{g})>\mathrm{K}_{2} \mathrm{CO}_{3}-\mathrm{AC}(103 \mathrm{mg} / \mathrm{g})>$ biochar $(83.5 \mathrm{mg} / \mathrm{g})$. The removal mechanism of $\mathrm{Cr}(\mathrm{V})$ from solution was regarded as an adsorption-coupled reduction, namely (1) partial reduction of $\mathrm{Cr}(\mathrm{VI})$ into $\mathrm{Cr}(\mathrm{III})$ during the adsorption process and (2) adsorption of the $\mathrm{Cr}(\mathrm{VI})$ anions through electrostatic attraction and pore filling and the reduced $\mathrm{Cr}$ (III) cations through complexation, $\mathrm{C} \pi$-cation interaction, cation exchange, and pore filing. Therefore, the prepared biochar and activated carbon can server as promising adsorbents to efficiently remove both $\mathrm{Cr}(\mathrm{VI})$ and $\mathrm{Cr}(\mathrm{III})$ from water.
\end{abstract}

Keywords: hydrothermal carbonization; activated carbon; biochar; adsorption mechanism; hexavalent chromium; adsorption-coupled reduction

\section{Introduction}

Industry often releases a large number of potentially toxic metals into surface water and groundwater. The existence of hexavalent chromium $(\mathrm{Cr}(\mathrm{VI}))$ - which is a strong oxidizing agent and highly toxic chemical substance-in the water environment has caused more potential health risk 
for human beings (especially cancer risks) [1,2]. This is because of its carcinogenic and mutagenic nature [3]. Meanwhile, $\mathrm{Cr}$ (III) that is classified as a hard acid can be easy to complex with some oxygen and donor ligands in solution [2]. Therefore, in 2004, WHO establishes a maximum allowable limit for total chromium (hexavalent chromium and trivalent chromium) concentration in drinking water at $50 \mu \mathrm{g} / \mathrm{L}$. Similarly, the US Environmental Protection Agency sets a limitation of total chromium concentrations at $100 \mu \mathrm{g} / \mathrm{L}$ for potable water [1].

As reported in the literature, hexavalent chromium can be efficiently eliminated from water media through many advanced methods. These potential water treatment technologies include ion exchange [1], chemical precipitation [4], chemical coagulation and electrocoagulation [5], electrochemical method [6], biological treatment [7], physical filtration process using nanofiltration and microfiltration [8], and adsorption [9]. Among these existing removal methods, adsorption might be a selection priority, because of its great advantages, such as a low operation cost, high regeneration capacity, and excellent efficiency of hexavalent and trivalent chromium removal from water media even at low concentrations [2,9-11]. In water treatment, activated carbon (AC) and biochar have been acknowledged as promising adsorbents to remove both $\mathrm{Cr}(\mathrm{VI})$ anions and $\mathrm{Cr}(\mathrm{III})$ cations from the water media and widely applied in many potable water purification and sewage treatment plants. This is presumably because they exhibit an excellent level of porosity (i.e., larger surface area and high total volume), a high concentration of oxygen-containing functional groups (i.e., carboxylic and phenolic), and high mechanical strength [12-17]. According to an industrial research report [18], the global demand for $\mathrm{AC}$ is expected to increase by $4.2 \%$ per year and be up to 2.2 million metric tons by 2022, and the global AC market size is estimated at approximately USD 4.75 billion in 2022. However, the high cost of commercial AC restricts their large-scale use in industries $[19,20]$.

In essence, AC can be prepared through a chemical or physical activation process. For the chemical activation, AC can be developed through some processes: one-stage, two-stage, and three-stage [21,22]. Although the one-stage chemical activation process is commonly used to prepare $\mathrm{AC}$, the two-stage one through pre-hydrothermal carbonization can produce AC with a higher density of micro-porosity and larger specific surface area than the others [14,16,22-24]. Moreover, biochar-a carbonaceous porous material that has a similar characterization to AC-has served as an effective-cost adsorbent for water and wastewater treatment [19]. In general, biochar can be directly prepared through a pyrolysis process under a certain oxygen-limited condition (one-stage process) $[17,19,20]$ or indirectly prepared though pre-hydrothermal carbonization and subsequent pyrolysis (two-stage process) [23,25]. Similar to AC, biochar was developed from the two-stage process exhibited a high concentration of micro-porosity [23].

Therefore, in this study, we developed advantageous activated carbons derived from the lignocellulosic wood chips of Tectona grandis sawdust tree through the two-stage activation process using $\mathrm{K}_{2} \mathrm{CO}_{3}$ or $\mathrm{ZnCl}_{2}$ as potential chemical activating reagents. In addition, Tectona grandis sawdust-derived biochar was prepared simultaneously without any presence of chemical activating reagent. They were applied to remove $\mathrm{Cr}(\mathrm{VI})$ from solution under different solution $\mathrm{pH}$ values and initial $\mathrm{Cr}(\mathrm{VI})$ concentrations. The relevant adsorption mechanism was also explored and proposed.

\section{Materials and Methods}

\subsection{Preparation of Biochar and Activated Carbon}

The tropical hardwood sawdusts of Tectona grandis tree-used as the feedstock (raw) material to prepare the carbonaceous materials-were collected, washed repeatedly with distilled deionized water, dried over-night at $80^{\circ} \mathrm{C}$, and then sieved into relatively uniform particles $(0.106-0.215 \mathrm{~mm})$. The carbonaceous porous materials were prepared through the two-stage process. First, approximately $10 \mathrm{~g}$ of the feedstock was mixed with distilled deionized water in a $150 \mathrm{~mL}$ beaker for $30 \mathrm{~min}$. Subsequently, the mixture was transferred into a Teflon autoclave and heated at $190{ }^{\circ} \mathrm{C}$ for $24 \mathrm{~h}$ to produce hydrochar. After the hydrothermal carbonization process, the brown hydrochar was 
filtrated, washed intensively with distilled deionized water, and dried over-night at $105^{\circ} \mathrm{C}$. Second, approximately $10 \mathrm{~g}$ of dried hydrochar (denoted as the precursor) was mixed with a certain activating agent $\left(\mathrm{K}_{2} \mathrm{CO}_{3}\right.$ or $\left.\mathrm{ZnCl}_{2}\right)$ at different impregnation ratios $(\mathrm{w} / \mathrm{w})$ of the activating reagent/precursor (i.e., $0.75: 1,1: 1,1.25: 1,1.75: 1$, and 2:1). The mixtures of activating reagent/precursor were then dried at $80^{\circ} \mathrm{C}$ for $24 \mathrm{~h}$ to remove water. Subsequently, they were pyrolyzed at $800^{\circ} \mathrm{C}$ for $4 \mathrm{~h}$ under an oxygen-limited condition (using a porcelain crucible covered with a lid) to obtain ACs. Notably, the biochar sample was directly prepared from hydrochar (without any activating agents) through the pyrolysis process at $800{ }^{\circ} \mathrm{C}$ for $4 \mathrm{~h}$.

The carbonaceous porous materials (i.e., biochar and AC) were washed with $0.1 \mathrm{M} \mathrm{HCl}$ and then distilled deionized water until the $\mathrm{pH}$ value of filtrate reached around 7.0. They were dried at $105^{\circ} \mathrm{C}$ until their moisture content was less than $5 \%$ and stored in some brown bottles until further use. Notably, a primary adsorption test demonstrated that the optimal impregnation ratio of the activating reagent/precursor was obtained at 1.75:1 for $\mathrm{ZnCl}_{2}$ and 0.75:1 for $\mathrm{K}_{2} \mathrm{CO}_{3}$. In other words, the $\mathrm{AC}$ samples prepared at the impregnation ratios of $\mathrm{ZnCl}_{2}$ :hydrochar (1.75:1; denoted as $\mathrm{ZnCl}_{2}-\mathrm{AC}$ ) and $\mathrm{K}_{2} \mathrm{CO}_{3}$ :hydrochar $\left(0.75: 1\right.$; denoted as $\left.\mathrm{K}_{2} \mathrm{CO}_{3}-\mathrm{AC}\right)$ exhibited an excellent adsorption capacity compared to those prepared at the other impregnation ratios (data not shown). As a result, the $\mathrm{AC}\left(\mathrm{ZnCl}_{2}-\mathrm{AC}\right.$ and $\mathrm{K}_{2} \mathrm{CO}_{3}-\mathrm{AC}$ ) and biochar (as the blank adsorbent) samples were characterized and used as selective adsorbents in this study. Furthermore, a commercial activated-charcoal (CAC, Norit RB4C) purchased from Sigma-Aldrich used for the comparison of the adsorption efficiency. The textural property of CAC has been published in our recent work [26].

\subsection{Characterization of Biochar and Activated Carbon}

The prepared carbonaceous materials were characterized by various advanced techniques. Their textural properties were calculated from the adsorption/desorption isotherm of nitrogen gas (Micromeritics ASAP 2020; ATS Scientific Inc., Burlington, ON, Canada). Scanning electron microscope (SEM; Hitachi S-3000N, Hitachi Scientific Instruments, Tokyo, Japan) was applied to analyze their surface morphology. The main elements on the surface of materials were determined by X-ray photoelectron spectroscopy (XPS; Thermo Fisher K-Alpha; the Thermo Scientific, Waltham, MA, USA). In addition, the XPS technique was applied to confirm the presence of chromium species on the surface of laden carbonaceous materials. This technique plays an important role in confirming the relevant adsorption mechanism. The surface charge of carbonaceous materials $\left(\mathrm{pH}_{\mathrm{PZC}}\right)$ was determined by the common drift method $[19,22,26]$.

\subsection{Batch Adsorption Study}

A stock solution $(1000 \mathrm{mg} / \mathrm{L})$ of $\mathrm{Cr}(\mathrm{VI})$ was prepared from pure potassium dichromate $\left(\mathrm{K}_{2} \mathrm{Cr}_{2} \mathrm{O}_{7}\right.$; purchased from SIGMA). The working $\mathrm{Cr}(\mathrm{VI})$ solutions were directly diluted from the stock solution. The adsorption process of $\mathrm{Cr}(\mathrm{VI})$ onto the carbonaceous porous materials was conducted under batch experiment. Approximately $0.02 \mathrm{~g}$ of adsorbent was added into a series of 150-mL Erlenmeyer Flask containing $50 \mathrm{~mL}$ of $\mathrm{Cr}(\mathrm{VI})$ at different initial $\mathrm{Cr}(\mathrm{VI})$ concentrations $(5-200 \mathrm{mg} / \mathrm{L})$. The $\mathrm{pH}$ value of the solution was adjusted and maintained during the adsorption process using $1 \mathrm{M} \mathrm{NaOH}$ and $1 \mathrm{M} \mathrm{HCl}$. The parafilm-covered flasks were shaken at $150 \mathrm{rpm}$ for $24 \mathrm{~h}$ at $30^{\circ} \mathrm{C}$. After the complete adsorption process, the mixture of laden adsorbent and adsorbate was separated by a glass fiber filter $(0.2-\mu \mathrm{m})$. The concentration of chromium in solution was determined by the atomic absorption spectrometry technique (Avanta/AAS, GBC). The AAS technique can determine the concentration of total chromium (hexavalent and trivalent chromium) in solution. The amount of chromium adsorbed onto the carbonaceous porous materials $\left(q_{\mathrm{e}} ; \mathrm{mg} / \mathrm{g}\right)$ at equilibrium was calculated based on the mass balance equation (Equation (1)).

$$
q_{\mathrm{e}}=\frac{C_{\mathrm{o}}-C_{\mathrm{e}}}{m} \times V,
$$


where $C_{\mathrm{o}}$ and $C_{\mathrm{e}}(\mathrm{mg} / \mathrm{L})$ are the chromium concentrations in solution at beginning and equilibrium, respectively; $m(\mathrm{~g})$ is the mass of used carbonaceous porous materials; and $V(\mathrm{~L})$ is the volume of the working chromium solution. All adsorption studies were conducted in triplicate, and the data were reported as average \pm standard deviation (SD).

\subsection{Adsorption Isotherm Model}

In general, the parameter of each adsorption isotherm model has different meanings. Depending on the main purposes of study, the isotherm model can be selected and applied for appreciation. In this study, we applied some common and helpful models to model the experimental data of adsorption equilibrium. They include the Langmuir [27], Freundlich [28], and Redlich-Peterson [29] models. In addition, to minimize the respective error functions, the non-linear optimization technique was used to calculate the relevant adsorption parameters of the selective models [30].

The Langmuir equation:

$$
q_{\mathrm{e}}=\frac{Q_{\max }^{\mathrm{o}} K_{\mathrm{L}} C_{\mathrm{e}}}{1+K_{\mathrm{L}} C_{\mathrm{e}}} .
$$

The Freundlich equation:

$$
q_{\mathrm{e}}=K_{\mathrm{F}} C_{\mathrm{e}}^{n} .
$$

The Redlich-Peterson model:

$$
q_{\mathrm{e}}=\frac{K_{\mathrm{RP}} C_{\mathrm{e}}}{1+a C_{\mathrm{e}}^{g}},
$$

where $Q^{\circ}$ max $(\mathrm{mg} / \mathrm{g})$ is the maximum saturated monolayer adsorption capacity of adsorbent; $K_{\mathrm{L}}(\mathrm{L} / \mathrm{mg})$ is the Langmuir constant related to the affinity between an adsorbent and adsorbate; $K_{\mathrm{F}}\left((\mathrm{mg} / \mathrm{g})(\mathrm{L} / \mathrm{mg})^{n}\right)$ is the Freundlich constant, which characterizes the strength of adsorption; $n$ (dimensionless) is a Freundlich intensity parameter; $K_{\mathrm{RP}}(\mathrm{L} / \mathrm{g})$ and $a_{\mathrm{RP}}(\mathrm{mg} / \mathrm{L})^{-g}$ are the Redlich-Peterson constants; and $g$ (dimensionless) is an exponent whose value must lie between 0 and 1.

\section{Results and Discussion}

\subsection{Property of Prepared Biochar and Activated Carbon}

Specific surface area plays a key role in estimating the adsorption capacity and mechanism of various contaminants onto a certain adsorbent. The determining method of specific surface area is often based on the nitrogen adsorption/desorption isotherm at $77 \mathrm{~K}$. The specific surface area $\left(S_{\mathrm{BET}} ; \mathrm{m}^{2} / \mathrm{g}\right)$ of a material is commonly determined by the Brunauer-Emmett-Teller (BET) equation. Meanwhile, the total pore volume often is calculated by the relevant amount of nitrogen adsorption at a relative pressure $\left(p / p^{\circ}\right)$ of around 0.99 [23]. Figure 1 provides the isotherms of nitrogen physisorption of three carbon samples. According to the International Union of Pure and Applied Chemistry (IUPAC) technical report [31], the gas physisorption isotherms can be classified as Type Ia for biochar and Type $\mathrm{Ib}$ for activated carbons $\left(\mathrm{K}_{2} \mathrm{CO}_{3}-\mathrm{AC}\right.$ and $\left.\mathrm{ZnCl}_{2}-\mathrm{AC}\right)$, suggesting that these materials exhibited a high quantity of micropore volume. Notably, a hysteresis appears in the multilayer range of the nitrogen physical adsorption isotherm by $\mathrm{ZnCl}_{2}-\mathrm{AC}$, implying that $\mathrm{ZnCl}_{2}-\mathrm{AC}$ exhibited a micropore or mesopore structure. 


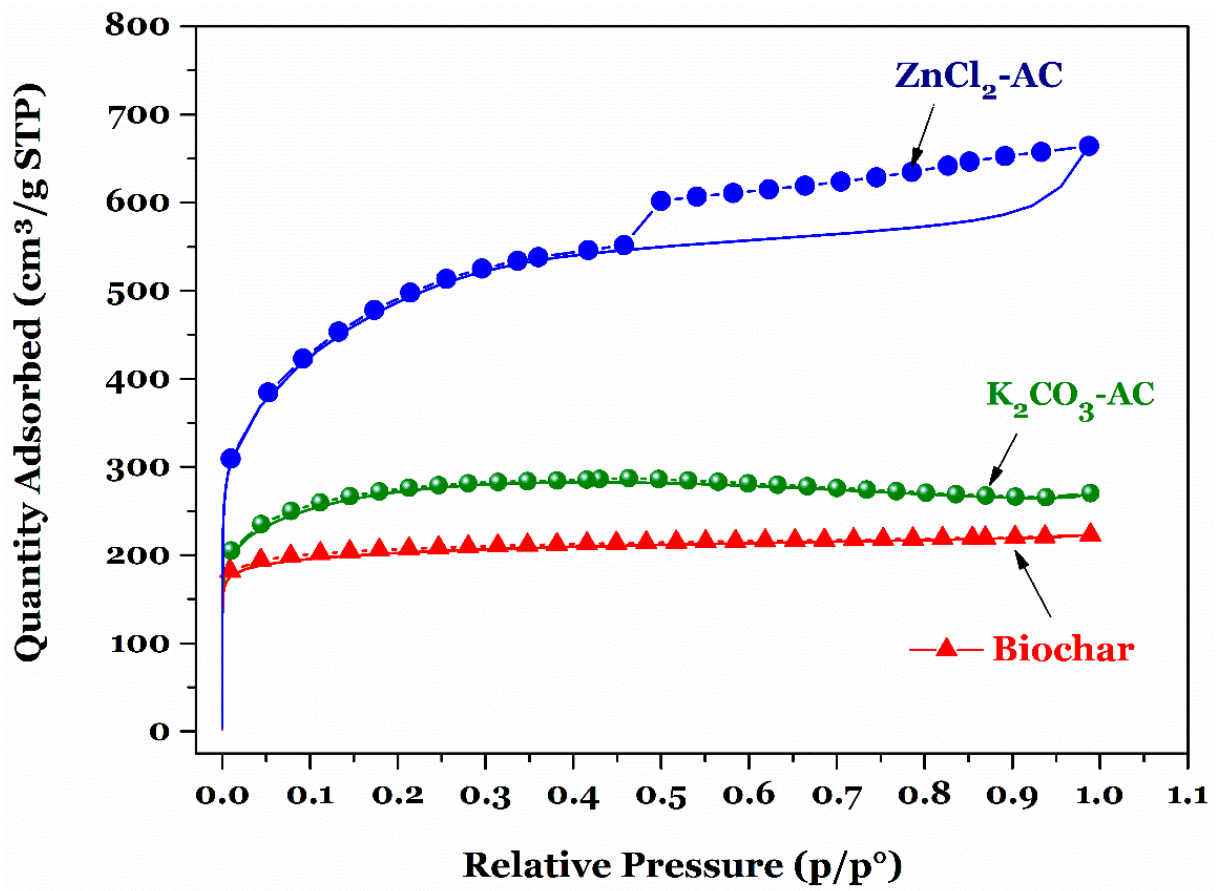

Figure 1. Nitrogen adsorption/desorption isotherm of the biochar and activated carbon (AC) samples.

Table 1 summaries some corresponding textural properties of three prepared samples. As expected, the chemical activation process (using $\mathrm{K}_{2} \mathrm{CO}_{3}$ and $\mathrm{ZnCl}_{2}$ as chemical activating agents) can effectively simulate the porosity development of the feedstock material compared to the pyrolysis process alone (without any chemical activating agents). The $S_{\text {BET }}$ values of three adsorbent solids decreased in the following order: $1757 \pm 8.81 \mathrm{~m}^{2} / \mathrm{g}\left(\mathrm{ZnCl}_{2}-\mathrm{AC}\right)>1013 \pm 1.62 \mathrm{~m}^{2} / \mathrm{g}\left(\mathrm{K}_{2} \mathrm{CO}_{3}-\mathrm{AC}\right)>792 \pm 0.52 \mathrm{~m}^{2} / \mathrm{g}$ (biochar). Therefore, it can be concluded that the $\mathrm{ZnCl}_{2}$ (an effective dehydration reagent) can act as a more effective chemical activating reagent than $\mathrm{K}_{2} \mathrm{CO}_{3}$ (a dehydrogenation reagent). An identical conclusion was obtained by Chen and coworkers [12] for the preparation of tobacco stem through chemical activation process using $\mathrm{K}_{2} \mathrm{CO}_{3}$ and $\mathrm{ZnCl}_{2}$. Three prepared carbonaceous porous materials with large specific surface area and high total pore volume (Table 1) were expected to have an outstanding adsorption capacity towards chromium ions in a water environment.

Table 1. Textural property of the prepared biochar and two activated carbon (AC) samples and CAC.

\begin{tabular}{cccc}
\hline Adsorbent & $S_{\text {BET }}\left(\mathbf{m}^{2} / \mathbf{g}\right)$ & $V_{\text {Total }}\left(\mathbf{c m}^{\mathbf{3}} / \mathbf{g}\right)$ & Pore Width $(\mathbf{n m})$ \\
\hline $\mathrm{ZnCl}_{2}-\mathrm{AC}$ & 1757 & 1.027 & 2.34 \\
$\mathrm{~K}_{2} \mathrm{CO}_{3}-\mathrm{AC}$ & 1013 & 0.418 & 1.65 \\
Commercial AC & 1026 & 0.502 & 1.95 \\
Biochar & 792 & 0.345 & 1.74 \\
\hline
\end{tabular}

The morphological property of the prepared samples was analyzed by the SEM technique. Figure 2 shows the different morphologies among there porous materials samples. The biochar sample exhibited a rough surface morphology with little porosity (Figure 2a). In contrast, the typical irregular and heterogeneous surface morphology with sponge-like structures were observed in the AC samples (Figure $2 \mathrm{~b}-\mathrm{c}$ ). The formation of well-developed pores in AC during pyrolysis was caused by the strong evaporation of $\mathrm{K}_{2} \mathrm{CO}_{3}$ or $\mathrm{ZnCl}_{2}$ under the high carbonization temperature of $800{ }^{\circ} \mathrm{C}$. Moreover, Figure $2 \mathrm{~d}$ indicates that the primary element composites were carbon and oxygen. Clearly, biochar and activated carbon are carbon-enriched materials that are approximately $86 \%$ to $91 \%$ carbon. In addition, three prepared samples had a high content of oxygen, suggesting that they might exhibit a high content of oxygen-containing functional groups on their surface $[12,13,15,32]$. The oxygen-bearing 
functionality has been known as the most active groups in adsorbing various potentially toxic metals through inner-sphere complexation and out-sphere complexation [33,34].
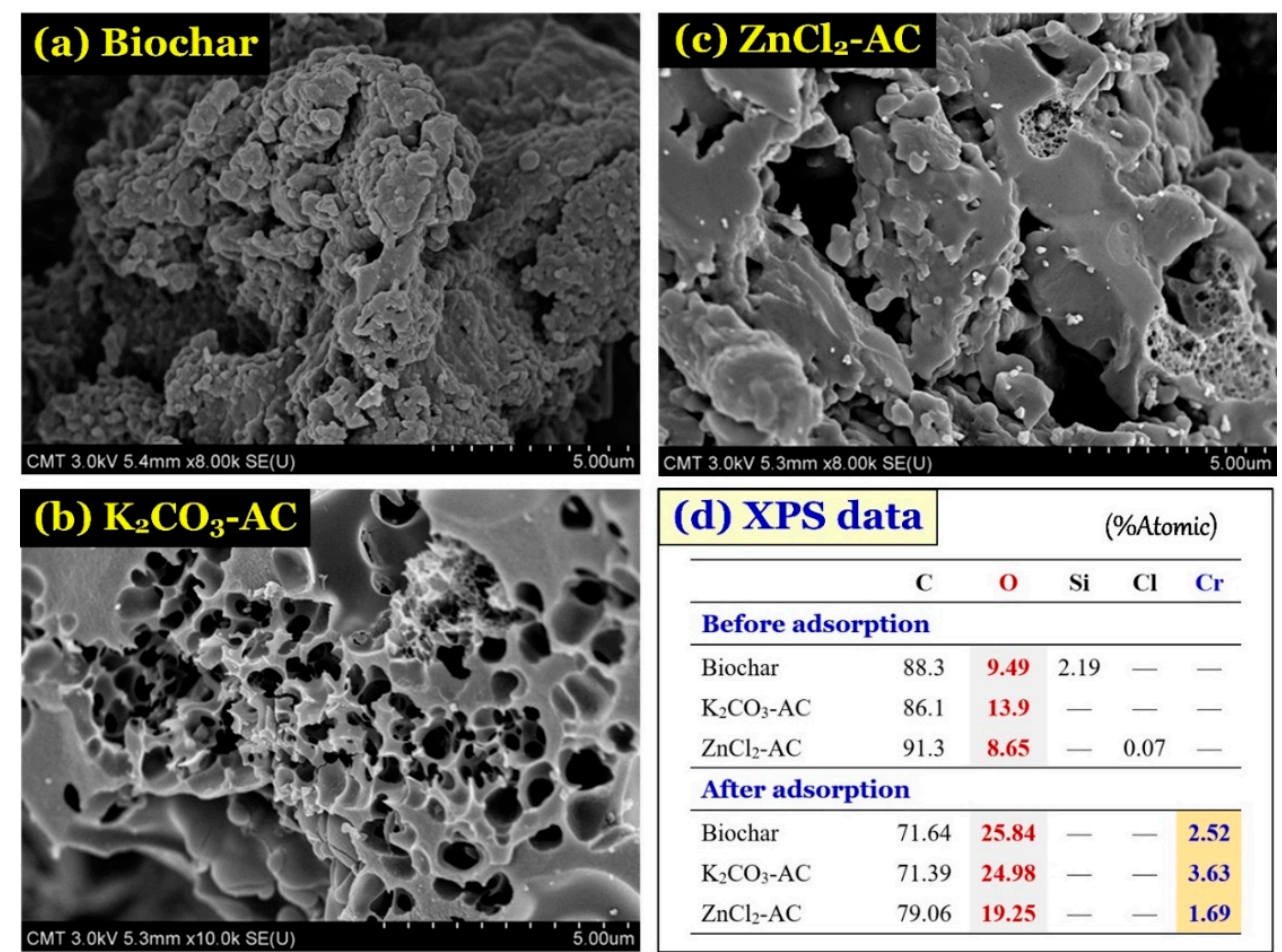

\begin{tabular}{|c|c|c|c|c|c|}
\hline \multicolumn{2}{|c|}{ d) XPS data } & \multirow[b]{2}{*}{$\mathbf{O}$} & \multicolumn{3}{|c|}{ (\%Atomic) } \\
\hline & $\mathrm{C}$ & & $\mathbf{S i}$ & $\mathrm{Cl}$ & $\mathrm{Cr}$ \\
\hline \multicolumn{6}{|c|}{ Before adsorption } \\
\hline Biochar & 88.3 & 9.49 & 2.19 & - & - \\
\hline $\mathrm{K}_{2} \mathrm{CO}_{3}-\mathrm{AC}$ & 86.1 & 13.9 & - & - & - \\
\hline $\mathrm{ZnCl}_{2}-\mathrm{AC}$ & 91.3 & 8.65 & - & 0.07 & - \\
\hline \multicolumn{6}{|c|}{ After adsorption } \\
\hline Biochar & 71.64 & 25.84 & - & - & 2.52 \\
\hline $\mathrm{K}_{2} \mathrm{CO}_{3}-\mathrm{AC}$ & 71.39 & 24.98 & - & - & 3.63 \\
\hline $\mathrm{ZnCl}_{2}-\mathrm{AC}$ & 79.06 & 19.25 & - & - & 1.69 \\
\hline
\end{tabular}

Figure 2. (a-c) Scanning electron microscope (SEM) image of biochar and activated carbons; and (d) their surface element component.

\subsection{Effect of $\mathrm{pH}$ on Adsorption Capacity of Prepared Biochar and Activated Carbon}

The solution $\mathrm{pH}$ is the most important parameter in the adsorption study because it greatly affects the dominant species of adsorbate and the surface charge of adsorbent under a working solution. According to the relative distribution of aqueous hexavalent chromium as a function of $\mathrm{pH}$ and $\mathrm{Cr}(\mathrm{VI})$ concentration, hydrogen chromate $\left(\mathrm{HCrO}_{4}{ }^{-}\right)$anion is regarded as the dominant anionic chromium species than the others $\left(\mathrm{H}_{2} \mathrm{CrO}_{4}, \mathrm{CrO}_{4}{ }^{2-}, \mathrm{Cr}_{2} \mathrm{O}_{7}{ }^{2-}\right.$, and $\left.\mathrm{HCr}_{2} \mathrm{O}_{7}{ }^{-}\right)$in a solution within the solution $\mathrm{pH}$ range from 1.0 to $6.5[2,9,35,36]$. In addition, when the chromium concentration in solution is higher than $1000 \mathrm{mg} / \mathrm{L}$, dichromate $\left(\mathrm{Cr}_{2} \mathrm{O}_{7}{ }^{2-}\right)$ anion is naturally formed in solution [2,35]. In this study, the maximum concentration of $\mathrm{Cr}(\mathrm{VI})$ is around $200 \mathrm{mg} / \mathrm{L}$; therefore, the dominant species of $\mathrm{Cr}(\mathrm{VI})$ in solution is $\mathrm{HCrO}_{4}{ }^{-}$anions. Moreover, the $\mathrm{pH}_{\mathrm{PZC}}$ values of prepared carbonaceous materials were higher than 8.0, suggesting that the surface charge of such materials was dominantly positive when the solution $\mathrm{pH}$ values were lower than 8.0. Therefore, $\mathrm{Cr}(\mathrm{VI})$ anions in solution can be electrostatically attracted by the positively charged surface of the carbon materials.

In general, to obtain the accurate comparison of adsorption efficiency of an adsorbate (i.e., potentially toxic metals) onto a certain adsorbent (i.e., carbon-based materials), the Langmuir maximum adsorption capacity ( $Q^{\mathrm{o}}$ max; calculated from Equation (2)) is often recommended instead of using the $q_{\mathrm{e}}$ value (obtained from Equation (1)) [2,30,37,38]. In addition, the experimental data of $\mathrm{Cr}(\mathrm{VI})$ adsorption onto the carbon materials well fitted the Langmuir model. Therefore, in this study, we discussed the $\mathrm{pH}$-dependence on the maximum adsorption capacity $\left(Q^{\mathrm{o}}{ }_{\max }\right)$ of the biochar and activated carbons (Figure 3). The results demonstrated that the adsorption capacity of three carbonaceous materials remarkably decreased when the solution $\mathrm{pH}$ values increased from 3.0 to 7.0. The decreasing adsorption capacity of the biochar and activated carbon at a higher solution $\mathrm{pH}$ value resulted from decreasing electrostatic attraction between the positively charged surface of materials (i.e., $-\mathrm{COOH}_{2}{ }^{+},-\mathrm{OH}_{2}{ }^{+}$, and $-\mathrm{NH}_{3}{ }^{+}$) and the $\mathrm{HCrO}_{4}{ }^{-}$anions in solution. A similar trend adsorption was reported by the other 
scholars for the adsorption of $\mathrm{Cr}(\mathrm{VI})$ onto biochar [10,11,15], prepared activated carbon [13,32,39-41], commercial activated carbon [41], and multiwalled carbon nanotubes [42].

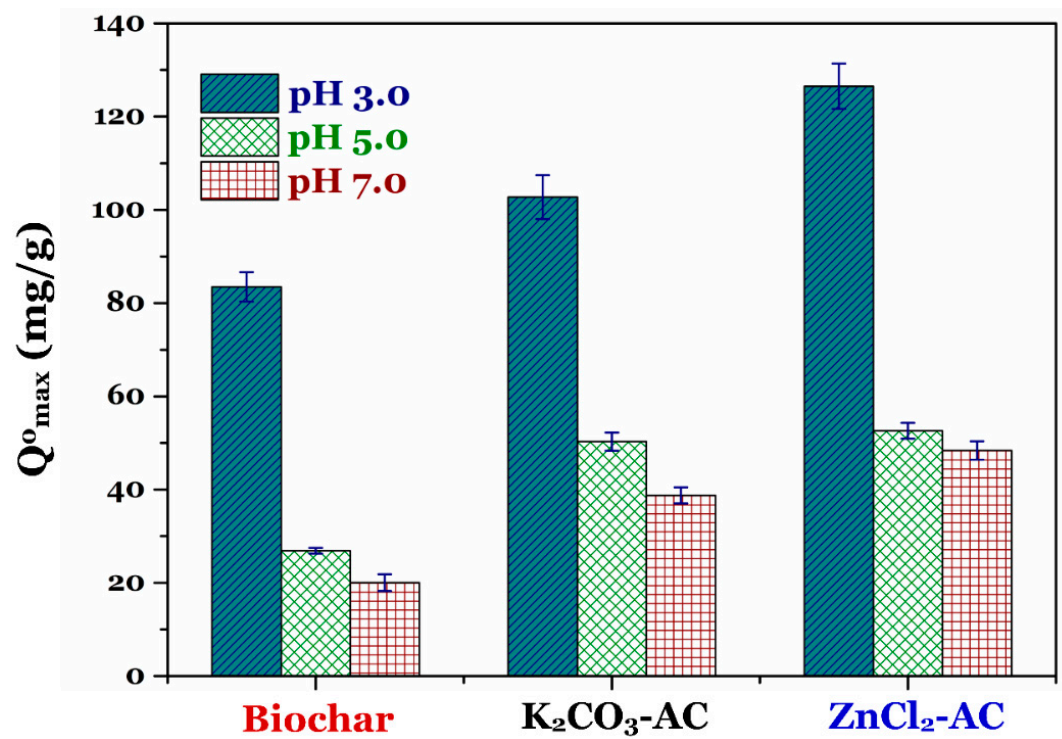

Figure 3. Effect of $\mathrm{pH}$ values on the Langmuir maximum adsorption capacity $\left(Q^{\mathrm{o}}\right.$ max; $\left.\mathrm{mg} / \mathrm{g}\right)$ of the prepared biochar and two activated carbons toward $\mathrm{Cr}(\mathrm{VI})$ in solution (Note: the data are represented as average \pm standard error).

\subsection{Adsorption Isotherm}

The adsorption isotherm plays an important role in identifying the region whether the experimental data of $\mathrm{Cr}(\mathrm{VI})$ adsorption onto the carbonaceous materials are located. According to [43], the adsorption isotherms of $\mathrm{Cr}(\mathrm{VI})$ by the prepared biochar and activated carbon (Figure 4) were classified as the $\mathrm{F}$ (Freundlich)-type or possible L(Langmuir)-type; a concave downward curve is typical identification of such types. The result suggested that the prepared carbonaceous materials exhibited a high affinity of chromium ions in the solution.

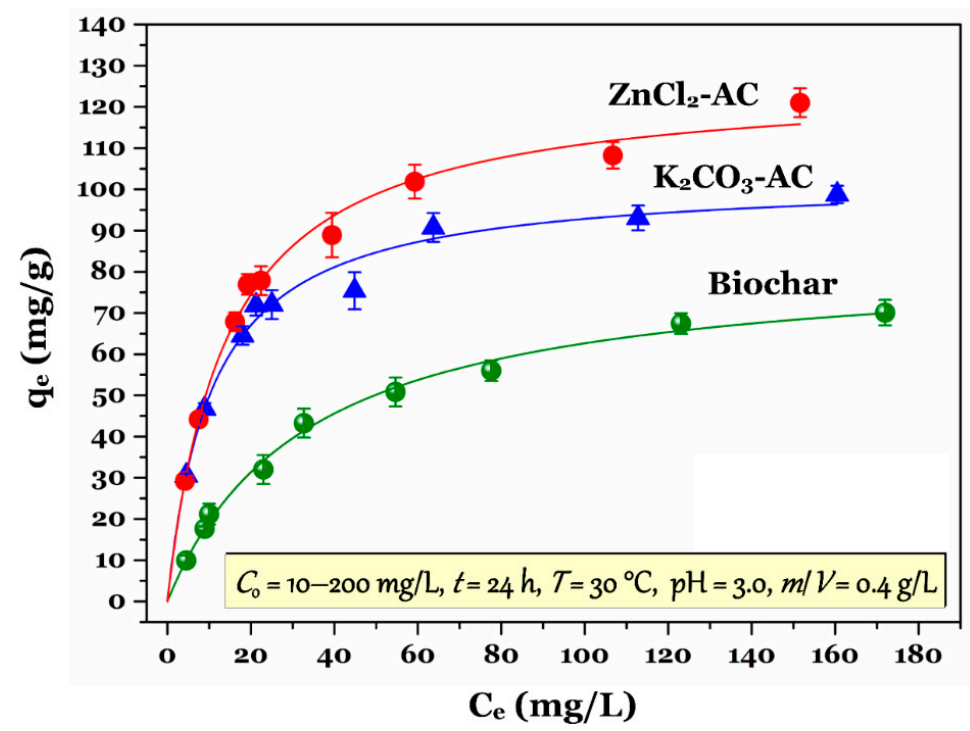

Figure 4. Adsorption isotherm of $\mathrm{Cr}(\mathrm{VI})$ by the prepared biochar and activated carbon samples (Note: the data are represented as average \pm standard deviation).

As shown in Table 2, the experimental data of adsorption equilibrium can be satisfactorily described by the selective models of adsorption isotherm, with the coefficient of determination $\left(R^{2}\right)$ 
being higher than 0.98 . Figure 4 shows the modeling of the Langmuir model for the experimental data under the given experiment conditions. According to the corresponding parameters of the Langmuir model in Table 2, the maximum adsorption capacity $\left(Q^{\circ}{ }_{m a x} ; \mathrm{mg} / \mathrm{g}\right)$ of the prepared carbonaceous porous adsorbents followed the decreasing order: $\mathrm{ZnCl}_{2}-\mathrm{AC}(127 \mathrm{mg} / \mathrm{g})>\mathrm{K}_{2} \mathrm{CO}_{3}-\mathrm{AC}(103 \mathrm{mg} / \mathrm{g})>$ biochar $(83.5 \mathrm{mg} / \mathrm{g})$. Clearly, the tendency of $\mathrm{Cr}(\mathrm{VI})$ adsorption onto the biochar and activated carbon samples (Table 2) was well consistent with that of their $S_{\mathrm{BET}}$ values (Table 1). Their specific surface area $\left(S_{\mathrm{BET}} ; \mathrm{m}^{2} / \mathrm{g}\right)$ values were ranked as follows: $\mathrm{ZnCl}_{2}-\mathrm{AC}\left(1757 \mathrm{~m}^{2} / \mathrm{g}\right)>\mathrm{K}_{2} \mathrm{CO}_{3}-\mathrm{AC}\left(1013 \mathrm{~m}^{2} / \mathrm{g}\right)$ $>$ biochar $\left(792 \mathrm{~m}^{2} / \mathrm{g}\right)$. This means that the activated carbon prepared through $\mathrm{ZnCl}_{2}$ activation exhibited an excellent adsorption capacity to $\mathrm{Cr}(\mathrm{VI})$ ions and large specific surface area compared to that through $\mathrm{K}_{2} \mathrm{CO}_{3}$ activation. In addition, the maximum adsorption capacity of the biochar and ACs was overwhelmingly higher than that of their precursor (hydrochar; $Q^{\circ}{ }_{\max }=4.5 \mathrm{mg} / \mathrm{g}$ ) and raw material (Tectona grandis sawdust biosorbent; $Q^{\circ}{ }_{\max }=3.8 \mathrm{mg} / \mathrm{g}$ ), confirming that the prepared carbonaceous porous materials exhibited a higher affinity toward chromium ions in the solution than their precursor and raw material. Interestingly, in the same experimental conditions, the prepared biochar and AC samples (83.5-127 mg/g) exhibited a higher Langmuir maximum adsorption capacity than commercial activated-charcoal $\mathrm{did}(52.6 \mathrm{mg} / \mathrm{g})$, suggesting that they have a potential application in large-scale industry.

Table 2. Corresponding parameter of chromium adsorption isotherms onto the biochar and ACs.

\begin{tabular}{|c|c|c|c|c|}
\hline & Unit & Biochar & $\mathrm{K}_{2} \mathrm{CO}_{3}-\mathrm{AC}$ & $\mathrm{ZnCl}_{2}-\mathrm{AC}$ \\
\hline \multicolumn{5}{|c|}{ 1. Langmuir model } \\
\hline$Q_{\text {max }}^{\mathrm{o}}$ & $(\mathrm{mg} / \mathrm{g})$ & 83.5 & 103 & 127 \\
\hline$K_{\mathrm{L}}$ & (L/mg) & 0.030 & 0.094 & 0.071 \\
\hline$R^{2}$ & - & 0.995 & 0.984 & 0.990 \\
\hline$\chi^{2}$ & - & 3.373 & 20.9 & 18.6 \\
\hline \multicolumn{5}{|c|}{ 2. Freundlich model } \\
\hline$K_{\mathrm{F}}$ & $(\mathrm{mg} / \mathrm{g})(\mathrm{L} / \mathrm{mg})^{\mathrm{n}}$ & 15.4 & 43.0 & 41.3 \\
\hline$n$ & - & 0.300 & 0.165 & 0.212 \\
\hline$R^{2}$ & - & 0.996 & 0.989 & 0.997 \\
\hline$\chi^{2}$ & - & 2.40 & 14.2 & 6.34 \\
\hline \multicolumn{5}{|c|}{ 3. Redlich-Peterson model } \\
\hline$K_{\mathrm{RP}}$ & $(\mathrm{L} / \mathrm{g})$ & 5.86 & 216 & 71.2 \\
\hline$a_{\mathrm{RP}}$ & $(\mathrm{mg} / \mathrm{L})$ & 0.212 & 4.86 & 1.54 \\
\hline$g$ & - & 0.802 & 0.841 & 0.809 \\
\hline$R^{2}$ & - & 0.996 & 0.986 & 0.996 \\
\hline$x^{2}$ & - & 2.66 & 18.9 & 8.24 \\
\hline
\end{tabular}

Notably, Figure 5a provides the XPS survey spectra of the biochar and ACs. The presence of $\mathrm{Cr}$ element on the spectra assuredly confirmed that chromium was successfully adsorbed by the carbon materials. In addition, the oxygen content of three adsorbent samples (\%atomic determined by X-ray photoelectron spectroscopy; Figure 2d) significantly increased after the adsorption of $\mathrm{Cr}(\mathrm{VI})$ in solution, namely increasing from $9.49 \%$ to $25.8 \%$ (for biochar), $13.9 \%$ to $25.0 \%$ (for $\mathrm{K}_{2} \mathrm{CO}_{3}-\mathrm{AC}$ ), and $8.6 \%$ to $19.3 \%$ (for $\mathrm{ZnCl}_{2}-\mathrm{AC}$ ). An analogous result was reported by Chen and colleagues [32] for the $\mathrm{Cr}(\mathrm{VI})$ adsorption by commercial activated carbon, they reported that the oxygen contents of commercial activated carbon (CAC) before and after adsorption of $\mathrm{Cr}(\mathrm{VI})$ was $18.4 \%$ and $20.5 \%$ (\%atomic determined by XPS), respectively. An increase in oxygen content of the biochar and activated carbon samples after adsorption resulted from the additional presence of oxygen element derived from the $\mathrm{HCrO}_{4}^{-}$oxyanions.

Furthermore, a comparison of the maximum adsorption capacity $\left(Q^{\circ} \max ; \mathrm{mg} / \mathrm{g}\right)$ of $\mathrm{Cr}(\mathrm{VI})$ onto the biochar and activated carbon samples in this study and other kinds of relevant adsorbent materials in 
the literature is provided in Table 3. The comparative performance corroborated that two activated carbons $(103-127 \mathrm{mg} / \mathrm{g})$ and biochar $(83.5 \mathrm{mg} / \mathrm{g})$ reported this study exhibited a higher $Q^{\circ}$ max value that most prepared activated carbons (23.6-55.2 mg/g), commercial activated carbons (48.5-52.6 mg/g), functionalized multiwalled carbon nanotubes $(85.8 \mathrm{mg} / \mathrm{g})$, and biochars $(2.15-24.6 \mathrm{mg} / \mathrm{g})$ in the previous studies. Accordingly, they are expected as a promising adsorbent for real application in removing chromium ions from water and wastewater.

Table 3. Comparison of the maximum adsorption capacity $\left(Q^{\circ}{ }_{m a x} ; \mathrm{mg} / \mathrm{g}\right)$ of the biochar and activated carbon in this study and the other corresponding adsorbents in the literature.

\begin{tabular}{|c|c|c|c|c|c|c|}
\hline & Stage & $\begin{array}{c}\text { Activating } \\
\text { Agent }\end{array}$ & $S_{\text {BET }}\left(\mathrm{m}^{2} / \mathrm{g}\right)$ & $\begin{array}{c}V_{\text {Total }} \\
\left(\mathrm{cm}^{3} / \mathrm{g}\right)\end{array}$ & $\begin{array}{l}Q^{\mathbf{o}} \max \\
(\mathrm{mg} / \mathrm{g})\end{array}$ & References \\
\hline \multicolumn{7}{|l|}{ 1. Activated carbon } \\
\hline Corn straw & One & $\mathrm{KOH}$ & 2131 & 1.128 & 176 & [13] \\
\hline Tectona grandis sawdust & Two & $\mathrm{ZnCl}_{2}$ & 1757 & 0.418 & 127 & This study \\
\hline Tectona grandis sawdust & Two & $\mathrm{K}_{2} \mathrm{CO}_{3}$ & 1013 & 1.027 & 103 & This study \\
\hline $\begin{array}{l}\text { Multiwalled carbon } \\
\text { nanotubes }\end{array}$ & - & - & 87.4 & 0.82 & 85.8 & [42] \\
\hline Waste tires & Two & $\mathrm{CO}_{2}$ & 832 & - & 55.2 & [41] \\
\hline NORIT RB4C (CAC) & Two & Steam & 1026 & 0.502 & 52.6 & This study \\
\hline F400 (CAC) & - & - & - & - & 48.5 & [41] \\
\hline Nutshells & One & $\mathrm{ZnCl}_{2}$ & 2869 & 1.96 & 46.2 & [39] \\
\hline Apple peels & One & $\mathrm{H}_{3} \mathrm{PO}_{4}$ & - & - & 36.0 & [40] \\
\hline \multicolumn{7}{|l|}{ 2. Biochar } \\
\hline Tectona grandis sawdust & Two & No & 792 & 0.345 & 83.5 & This study \\
\hline Wheat straw & One & No & 26.3 & - & 24.6 & [11] \\
\hline Wicke & One & No & 11.4 & - & 23.6 & [11] \\
\hline Banana pseudostem & One & No & 8.53 & 0.044 & 21.5 & [15] \\
\hline Sawdust & One & No & 320 & - & 2.15 & [41] \\
\hline
\end{tabular}

Notes: The preparation method (in the Stage column): one-stage process (feed stock was directly polysized) and two-stage process (feed stock was pre-treated through hydrothermal carbonization and subsequently pyrolyzed). CAC means commercial activated carbon.

\subsection{Adsorption Mechanism}

As aforementioned, the solution $\mathrm{pH}$ has a strong effect on the adsorption mechanism of chromium. In this study, the adsorption mechanism of chromium (the dominant $\mathrm{HCrO}_{4}{ }^{-}$species) was explored at solution $\mathrm{pH} 3.0$ because three prepared adsorbents exhibited excellent adsorption capacity under this condition (Figure 3). The biochar and ACs samples possessed large specific surface area and high total pore volume (Table 1). In general, an adsorbent with excellent textural property has been acknowledged to exhibit an outstanding adsorption capacity to various contaminants (including hexavalent chromium and trivalent chromium) through the integral adsorption mechanism of pore-filling.

In essence, when $\mathrm{Cr}(\mathrm{VI})$ oxyanions in solution are in contact with some certain functionality (acting as electron-donor groups such as $-\mathrm{COOH},-\mathrm{OH}$, and $-\mathrm{NH}_{2}$ ) on the surface of the adsorbent, they are naturally reduced to less toxic $\mathrm{Cr}(\mathrm{III})$ cations through the common redox reaction. This is because $\mathrm{Cr}(\mathrm{VI})$ has a high redox (oxidation/reduction) potential value (usually higher than $+1.35 \mathrm{~V}$ ) under standard conditions [9,30,44,45]. In this study, the electrons in Equation (5) were provided by the oxygen-containing functional groups on the surface of biochar and activated carbon.

$$
\mathrm{HCrO}_{4}^{-}+7 \mathrm{H}^{+}+3 \mathrm{e}^{-} \rightleftharpoons \mathrm{Cr}^{3+}+4 \mathrm{H}_{2} \mathrm{O}\left(E^{\circ}=+1.35\right) .
$$



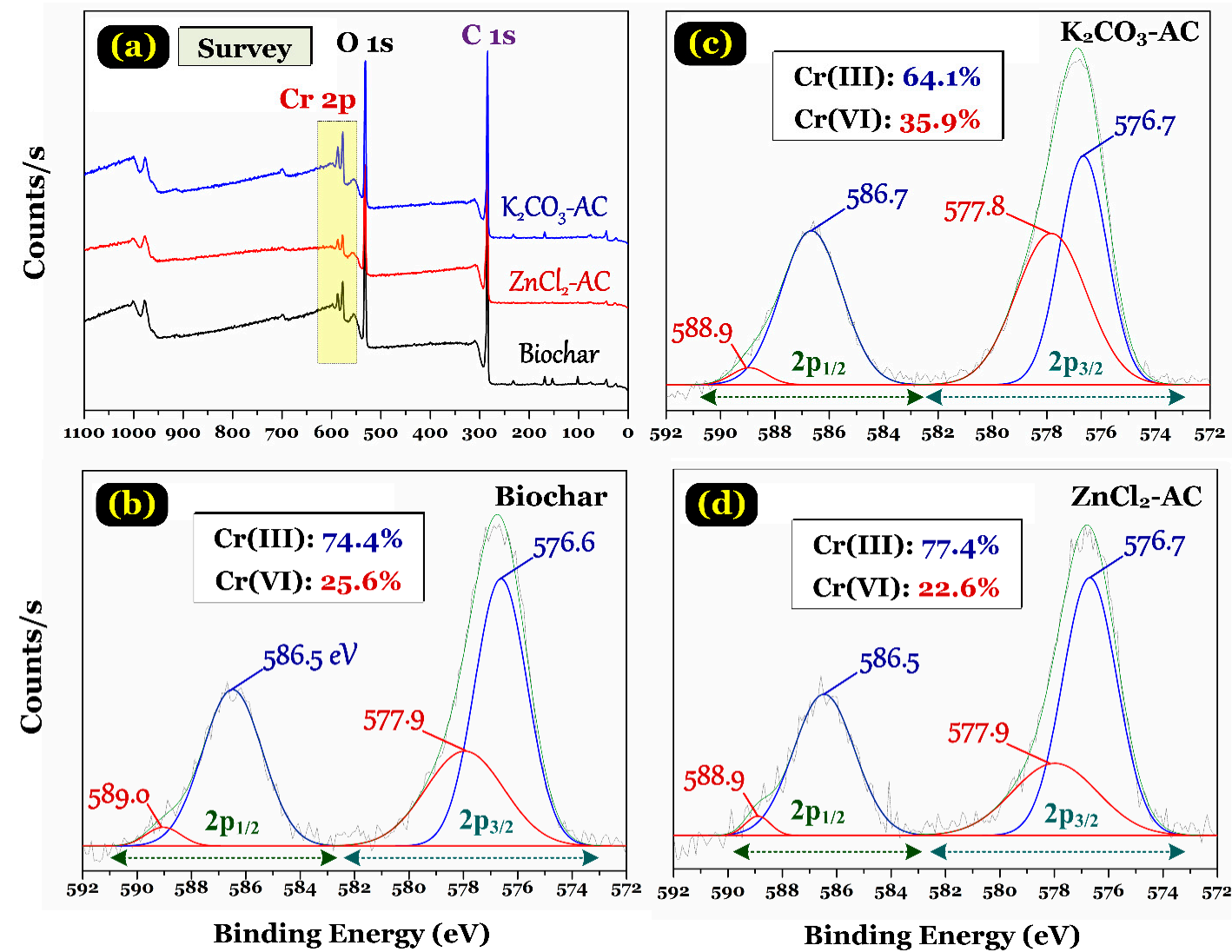

Figure 5. (a) X-ray photoelectron spectroscopy (XPS) survey spectrum of the prepared biochar and two activated carbon samples, and (b-d) high-resolution spectrum of $\mathrm{Cr} 2 \mathrm{p}$ in these samples. (Note: the initial $\mathrm{Cr}(\mathrm{VI})$ concentration is approximately $200 \mathrm{mg} / \mathrm{L}$ ).

However, if reduced $\mathrm{Cr}(\mathrm{III})$ does not present on the surface of the prepared carbon materials, the adsorption mechanism will only involve the adsorption of $\mathrm{Cr}(\mathrm{VI})$ oxyanions. In contrast, if both reduced $\mathrm{Cr}(\mathrm{III})$ and $\mathrm{Cr}(\mathrm{VI})$ ions co-exist on the materials' surface, the adsorption mechanism will be an "adsorption-coupled reduction" $[9,32,42,45]$. To confirm the oxidation state and coordination environment of chromium bound to the biochar and activated carbon samples, the XPS analysis of such materials after adsorbing $\mathrm{Cr}(\mathrm{VI})$ was conducted. The narrow spectra of $\mathrm{Cr} 2 \mathrm{p}$ XPS indicated the coexistence of $\mathrm{Cr}(\mathrm{VI})$ and $\mathrm{Cr}(\mathrm{III})$ on the surface of the adsorbents (Figure $5 \mathrm{~b}-\mathrm{d}$ ). Taking $\mathrm{ZnCl}_{2}-\mathrm{AC}$ as a typical example, $\mathrm{Cr}(\mathrm{VI})$ was identified at the binding energy of $577.9 \mathrm{eV}\left(\mathrm{Cr} 2 \mathrm{p}_{3 / 2}\right)$ and $588.9 \mathrm{eV}(\mathrm{Cr}$ $\left.2 \mathrm{p}_{1 / 2}\right)$; meanwhile, $\mathrm{Cr}(\mathrm{III})$ was $576.7 \mathrm{eV}\left(\mathrm{Cr} 2 \mathrm{p}_{3 / 2}\right)$ and $586.5 \mathrm{eV}\left(\mathrm{Cr} 2 \mathrm{p}_{1 / 2}\right)$. Clearly, the binding energy of $\mathrm{Cr}(\mathrm{III})$ was lower than that of $\mathrm{Cr}(\mathrm{VI})$, which is well consistent with the previous literature $[15,36,46,47]$ and some critical comment works $[48,49]$. Similarly, some authors investigated the binding energy of relevant standard chemicals (i.e., $\mathrm{K}_{2} \mathrm{Cr}_{2} \mathrm{O}_{7}$ and $\mathrm{CrCl}_{3}$ as the blank samples) by the XPS techniques. They also conduced that $\mathrm{Cr}(\mathrm{VI})$ exhibited a higher binding energy than $\mathrm{Cr}(\mathrm{III})$ because hexavalent chromium is more electrophilic than $\mathrm{Cr}$ (III) [46,47]. Notably, the mechanism of $\mathrm{Cr}(\mathrm{VI})$ removal from water media by various adsorbents through adsorption-coupled reduction has been confirmed by many scholars, such as activated carbon [13,32], multiwalled carbon nanotubes [42], biochar [15,47], layered double hydroxides [32,36], graphene oxide [50], and even biosorbent [46,51].

Notably, Figure 5 shows that the $\mathrm{Cr}$ (III) metal is the dominant species present on the surface of three carbon samples, with the percentage of $\mathrm{Cr}$ (III) accounting for $77.4 \%\left(\mathrm{ZnCl}_{2}-\mathrm{AC}\right), 74.4 \%$ (biochar), $64.1 \%\left(\mathrm{~K}_{2} \mathrm{CO}_{3}-\mathrm{AC}\right)$. The result suggested that the majority of $\mathrm{Cr}(\mathrm{VI})$ anions was reduced to less toxic $\mathrm{Cr}$ (III) cations, and the reduced $\mathrm{Cr}$ (III) was adequately adsorbed by the biochar and the activated carbon samples rather than $\mathrm{Cr}(\mathrm{VI})$. Similarly, some scholars found that after the $\mathrm{Cr}(\mathrm{VI})$ adsorption, the percentage of $\mathrm{Cr}(\mathrm{III})$ on the surface of laden adsorbent (using XPS technique) was approximately $97.1 \%$ 
for the biochar adsorbent [15] and 78.9\% for the AC adsorbent [32]. According to the literature, the $\mathrm{Cr}^{3+}$ metal ions can be adsorbed by carbonaceous porous material through (1) cation $-\pi$ interaction (also known as $C \pi$-cation interaction) between the aromatic $\pi$-system in the carbon samples and metallic $\mathrm{Cr}$ (III) cation [42,52], (2) complexation with the oxygen-containing functional groups (i.e., carboxyl and phenolic groups) $[15,50,53]$, cation exchange with alkaline $\left(\mathrm{K}^{+}\right.$and $\left.\mathrm{Na}^{+}\right)$and alkaline earth $\left(\mathrm{Ca}^{2+}\right.$ and $\mathrm{Mg}^{2+}$ ) metal ions [15,51], and (3) pore filling [32]. In addition, although the adsorption mechanism of $\mathrm{Cr}(\mathrm{III})$ involved in the precipitation of $\mathrm{Cr}(\mathrm{OH})_{3}$ on the surface of carbon material (i.e., biochar and multiwalled carbon nanotubes) has been reported in the literature works [15,42], this mechanism was ruled out in this study. This is because the adsorption study was conducted under the acidic condition.

To sum up, the removal mechanism of $\mathrm{Cr}(\mathrm{VI})$ by the biochar and activated carbon samples was the principle adsorption-coupled reduction (Figure 6). Namely, $\mathrm{Cr}(\mathrm{VI})$ ions solution were partially reduced into $\mathrm{Cr}(\mathrm{III})$ ions during the process of $\mathrm{Cr}(\mathrm{VI})$ adsorption. The adsorption mechanism of $\mathrm{Cr}(\mathrm{VI})$ primarily involved the electrostatic attraction and pore filling; meanwhile, that of $\mathrm{Cr}(\mathrm{III})$ was the complexation, $\mathrm{C} \pi$ - cation, cation exchange, and pore filling.

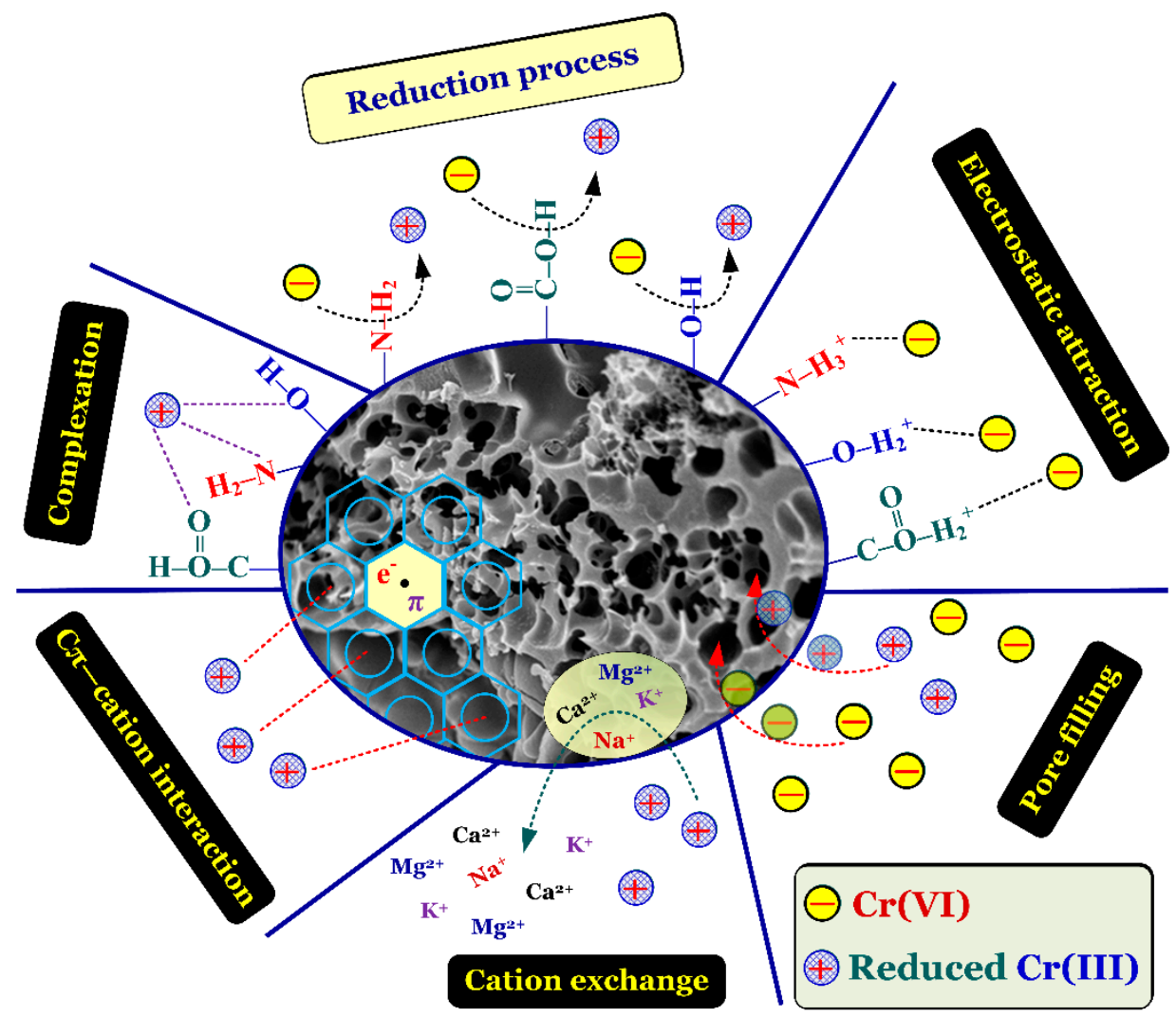

Figure 6. Proposed removal mechanism (adsorption-coupled reduction) of chromium by the carbonaceous porous materials.

\section{Conclusions}

The $\mathrm{Cr}(\mathrm{VI})$ contaminant in solution was efficiently removed by three carbonaceous porous materials. Under the same adsorptive experiment conditions, the maximum adsorption capacity $\left(Q_{\text {max }}^{\mathrm{o}}\right)$ of chromium was ordered as follows: $\mathrm{ZnCl}_{2}-\mathrm{AC}(127 \mathrm{mg} / \mathrm{g})>\mathrm{K}_{2} \mathrm{CO}_{3}-\mathrm{AC}(103 \mathrm{mg} / \mathrm{g})>$ biochar $(84 \mathrm{mg} / \mathrm{g})$, which is consistent with the order of specific surface area $\left(S_{\mathrm{BET}}\right): 1757 \mathrm{~m}^{2} / \mathrm{g}>1013 \mathrm{~m}^{2} / \mathrm{g}>$ $792 \mathrm{~m}^{2} / \mathrm{g}$, respectively. The adsorption mechanism of chromium ions onto the carbonaceous porous material was relatively similar and primarily regarded as adsorption-coupled reduction. During the process of $\mathrm{Cr}(\mathrm{VI})$ adsorption, $\mathrm{Cr}(\mathrm{VI})$ was partially reduced into $\mathrm{Cr}(\mathrm{III})$ through the redox reaction. A part of un-reduced $\mathrm{Cr}(\mathrm{VI})$ anions was adsorbed by the carbonaceous porous materials through electrostatic attraction (mainly between $\mathrm{HCrO}_{4}{ }^{-}$anions and the $-\mathrm{COOH}_{2}{ }^{+}$and $-\mathrm{OH}_{2}{ }^{+}$groups on 
the materials' surface) and pore filing. Meanwhile, the reduced $\mathrm{Cr}(\mathrm{III})$ cations were adsorbed by the carbonaceous porous through complexation with the main oxygen-containing functional groups on the materials' surface, $\mathrm{C} \pi$-cation interaction, cation exchange, and pore filing. It can be concluded that the process of two-stage preparation can produce biochar and activated carbon with a high micro-porosity, large specific surface area, and excellent adsorption capacity to chromium ions in solution.

Author Contributions: The paper was written with the contributions of all co-authors. All authors share equal contributions in this work. A.T.V. contributed substantially to the design of the study, the analyses, validation, and interpretation of experimental data, and the original draft preparation. V.P.N. did the experiments and interpreted experimental data. A.O. took responsibility for methodology and software. A.N. and B.T.D.J. played an integral role in the formal analysis and English corrections. H.N.T. analysed and verified the experimental data, made the figures, wrote the manuscript, replied to comments, and corrected the proof. H.-P.C. contributed to the supervision, conceptualization, validation, interpretation, project administration, and funding acquisition. All authors have read and approved the submission.

Funding: This research received no external funding.

Acknowledgments: Thanks to Chung Yuan Christian University for technical and financial supports.

Conflicts of Interest: The authors declare no conflict of interest.

\section{References}

1. Korak, J.A.; Huggins, R.; Arias-Paic, M. Regeneration of pilot-scale ion exchange columns for hexavalent chromium removal. Water Res. 2017, 118, 141-151. [CrossRef] [PubMed]

2. Mohan, D.; Pittman, C.U. Activated carbons and low cost adsorbents for remediation of tri- and hexavalent chromium from water. J. Hazard. Mater. 2006, 137, 762-811. [CrossRef]

3. Aharchaou, I.; Py, J.-S.; Cambier, S.; Loizeau, J.-L.; Cornelis, G.; Rousselle, P.; Battaglia, E.; Vignati, D.A.L. Chromium hazard and risk assessment: New insights from a detailed speciation study in a standard test medium. Environ. Toxicol. Chem. 2018, 37, 983-992. [CrossRef] [PubMed]

4. Yan, K.; Liu, Z.; Li, Z.; Yue, R.; Guo, F.; Xu, Z. Selective separation of chromium from sulphuric acid leaching solutions of mixed electroplating sludge using phosphate precipitation. Hydrometallurgy 2019, 186, 42-49. [CrossRef]

5. Martín-Domínguez, A.; Rivera-Huerta, M.L.; Pérez-Castrejón, S.; Garrido-Hoyos, S.E.; Villegas-Mendoza, I.E.; Gelover-Santiago, S.L.; Drogui, P.; Buelna, G. Chromium removal from drinking water by redox-assisted coagulation: Chemical versus electrocoagulation. Sep. Purif. Technol. 2018, 200, 266-272. [CrossRef]

6. Tu, J.; Gan, Y.; Liang, T.; Wan, H.; Wang, P. A miniaturized electrochemical system for high sensitive determination of chromium(VI) by screen-printed carbon electrode with gold nanoparticles modification. Sens. Actuators B Chem. 2018, 272, 582-588. [CrossRef]

7. Mamais, D.; Noutsopoulos, C.; Kavallari, I.; Nyktari, E.; Kaldis, A.; Panousi, E.; Nikitopoulos, G.; Antoniou, K.; Nasioka, M. Biological groundwater treatment for chromium removal at low hexavalent chromium concentrations. Chemosphere 2016, 152, 238-244. [CrossRef]

8. Zolfaghari, G.; Kargar, M. Nanofiltration and microfiltration for the removal of chromium, total dissolved solids, and sulfate from water. MethodsX 2019, 6, 549-557. [CrossRef]

9. Tran, H.N.; Nguyen, D.T.; Le, G.T.; Tomul, F.; Lima, E.C.; Woo, S.H.; Sarmah, A.K.; Nguyen, H.Q.; Nguyen, P.T.; Nguyen, D.D.; et al. Adsorption mechanism of hexavalent chromium onto layered double hydroxides-based adsorbents: A systematic in-depth review. J. Hazard. Mater. 2019, 373, 258-270. [CrossRef]

10. Wang, H.; Zhang, M.; Lv, Q. Removal efficiency and mechanism of $\mathrm{Cr}(\mathrm{VI})$ from aqueous solution by maize straw biochars derived at different pyrolysis temperatures. Water 2019, 11, 781. [CrossRef]

11. Tytłak, A.; Oleszczuk, P.; Dobrowolski, R. Sorption and desorption of $\mathrm{Cr}(\mathrm{VI})$ ions from water by biochars in different environmental conditions. Environ. Sci. Pollut. Res. 2015, 22, 5985-5994. [CrossRef] [PubMed]

12. Chen, R.; Li, L.; Liu, Z.; Lu, M.; Wang, C.; Li, H.; Ma, W.; Wang, S. Preparation and characterization of activated carbons from tobacco stem by chemical activation. J. Air Waste Manag. Assoc. 2017, 67, 713-724. [CrossRef] [PubMed]

13. Ma, H.; Yang, J.; Gao, X.; Liu, Z.; Liu, X.; Xu, Z. Removal of chromium (VI) from water by porous carbon derived from corn straw: Influencing factors, regeneration and mechanism. J. Hazard. Mater. 2019, 369, 550-560. [CrossRef] [PubMed] 
14. Tran Hai, N.; Huang, F.-C.; Lee, C.-K.; Chao, H.-P. Activated carbon derived from spherical hydrochar functionalized with triethylenetetramine: Synthesis, characterizations, and adsorption application. Green Process. Synth. 2017, 6, 565. [CrossRef]

15. Xu, S.; Yu, W.; Liu, S.; Xu, C.; Li, J.; Zhang, Y. Adsorption of hexavalent chromium using banana pseudostem biochar and its mechanism. Sustainability 2018, 10, 4250. [CrossRef]

16. Huang, F.-C.; Lee, C.-K.; Han, Y.-L.; Chao, W.-C.; Chao, H.-P. Preparation of activated carbon using micro-nano carbon spheres through chemical activation. J. Taiwan Inst. Chem. Eng. 2014, 45, 2805-2812. [CrossRef]

17. Boakye, P.; Tran, H.N.; Lee, D.S.; Woo, S.H. Effect of water washing pretreatment on property and adsorption capacity of macroalgae-derived biochar. J. Environ. Manag. 2019, 233, 165-174. [CrossRef]

18. Freedonia. Global Activated Carbon-Demand and Sales Forecasts, Market Share, Market Size, Market Leaders; The Freedonia Group: Cleveland, OH, USA, 2018.

19. Tran, H.N.; You, S.-J.; Chao, H.-P. Effect of pyrolysis temperatures and times on the adsorption of cadmium onto orange peel derived biochar. Waste Manag. Res. 2016, 34, 129-138. [CrossRef]

20. Tran, H.N.; Wang, Y.; You, S.; Chao, H. Sustainable biochar derived from agricultural wastes for removal of methylene green 5 from aqueous solution: Adsorption kinetics, isotherms, thermodynamics, and mechanism analysis. In Air, Gas, and Water Pollution Control Using Industrial and Agricultural Solid Wastes Adsorbents, 1st ed.; CRC Press: Boca Raton, FL, USA, 2017; pp. 255-291.

21. Tran, H.N.; You, S.-J.; Chao, H.-P. Fast and efficient adsorption of methylene green 5 on activated carbon prepared from new chemical activation method. J. Environ. Manag. 2017, 188, 322-336. [CrossRef]

22. Tran, H.N.; Wen, Y.-C.; Wang, Y.-F.; You, S.-J. Highly efficient removal of hazardous aromatic pollutants by micro-nano spherical carbons synthesized from different chemical activation methods: A comparison study. Environ. Technol. 2019, 40, 1376-1391. [CrossRef]

23. Tran, H.N.; Lee, C.-K.; Nguyen, T.V.; Chao, H.-P. Saccharide-derived microporous spherical biochar prepared from hydrothermal carbonization and different pyrolysis temperatures: Synthesis, characterization, and application in water treatment. Environ. Technol. 2018, 39, 2747-2760. [CrossRef] [PubMed]

24. Sevilla, M.; Fuertes, A.B.; Mokaya, R. High density hydrogen storage in superactivated carbons from hydrothermally carbonized renewable organic materials. Energy Environ. Sci. 2011, 4, 1400-1410. [CrossRef]

25. Tran, H.N.; Lee, C.-K.; Vu, M.T.; Chao, H.-P. Removal of copper, lead, methylene green 5, and acid red 1 by saccharide-derived spherical biochar prepared at low calcination temperatures: Adsorption kinetics, isotherms, and thermodynamics. Water Air Soil Pollut. 2017, 228, 401-417. [CrossRef]

26. Tran, H.N.; Wang, Y.-F.; You, S.-J.; Chao, H.-P. Insights into the mechanism of cationic dye adsorption on activated charcoal: The importance of $\pi-\pi$ interactions. Process. Saf. Environ. Prot. 2017, 107, 168-180. [CrossRef]

27. Langmuir, I. The adsorption of gases on plane surfaces of glass, mica and platinum. J. Am. Chem. Soc. 1918, 40, 1361-1403. [CrossRef]

28. Freundlich, H. Über die adsorption in lösungen. Z. Phys. Chem. 1907, 57, 385-470. [CrossRef]

29. Redlich, O.; Peterson, D.L. A useful adsorption isotherm. J. Phys. Chem. 1959, 63, 1024. [CrossRef]

30. Tran, H.N.; You, S.-J.; Hosseini-Bandegharaei, A.; Chao, H.-P. Mistakes and inconsistencies regarding adsorption of contaminants from aqueous solutions: A critical review. Water Res. 2017, 120, 88-116. [CrossRef] [PubMed]

31. Thommes, M.; Kaneko, K.; Neimark Alexander, V.; Olivier James, P.; Rodriguez-Reinoso, F.; Rouquerol, J.; Sing Kenneth, S.W. Physisorption of gases, with special reference to the evaluation of surface area and pore size distribution (IUPAC Technical Report). Pure Appl. Chem. 2015, 87, 1051-1069. [CrossRef]

32. Chen, Y.; An, D.; Sun, S.; Gao, J.; Qian, L. Reduction and Removal of Chromium VI in Water by Powdered Activated Carbon. Materials 2018, 11, 269. [CrossRef]

33. Tran, H.N.; You, S.-J.; Chao, H.-P. Thermodynamic parameters of cadmium adsorption onto orange peel calculated from various methods: A comparison study. J. Environ. Chem. Eng. 2016, 4, 2671-2682. [CrossRef]

34. Tran, H.N.; Chao, H.-P. Adsorption and desorption of potentially toxic metals on modified biosorbents through new green grafting process. Environ. Sci. Pollut. Res. 2018, 25, 12808-12820. [CrossRef]

35. Sengupta, A.K.; Clifford, D. Chromate ion exchange mechanism for cooling water. Ind. Eng. Chem. Fundam. 1986, 25, 249-258. [CrossRef] 
36. Chao, H.-P.; Wang, Y.-C.; Tran, H.N. Removal of hexavalent chromium from groundwater by Mg/Al-layered double hydroxides using characteristics of in-situ synthesis. Environ. Pollut. 2018, 243, 620-629. [CrossRef] [PubMed]

37. Volesky, B. Biosorption and me. Water Res. 2007, 41, 4017-4029. [CrossRef] [PubMed]

38. Tran, H.N.; Lin, C.-C.; Chao, H.-P. Amino acids-intercalated Mg/Al layered double hydroxides as dual-electronic adsorbent for effective removal of cationic and oxyanionic metal ions. Sep. Purif. Technol. 2018, 192, 36-45. [CrossRef]

39. Kumar, A.; Jena, H.M. Adsorption of $\mathrm{Cr}(\mathrm{VI})$ from aqueous phase by high surface area activated carbon prepared by chemical activation with $\mathrm{ZnCl2}$. Process. Saf. Environ. Prot. 2017, 109, 63-71. [CrossRef]

40. Enniya, I.; Rghioui, L.; Jourani, A. Adsorption of hexavalent chromium in aqueous solution on activated carbon prepared from apple peels. Sustain. Chem. Pharm. 2018, 7, 9-16. [CrossRef]

41. Hamadi, N.K.; Chen, X.D.; Farid, M.M.; Lu, M.G.Q. Adsorption kinetics for the removal of chromium(VI) from aqueous solution by adsorbents derived from used tyres and sawdust. Chem. Eng. J. 2001, 84, 95-105. [CrossRef]

42. Krishna Kumar, A.S.; Jiang, S.-J.; Tseng, W.-L. Effective adsorption of chromium(VI)/Cr(III) from aqueous solution using ionic liquid functionalized multiwalled carbon nanotubes as a super sorbent. J. Mater. Chem. A 2015, 3, 7044-7057. [CrossRef]

43. Moreno-Castilla, C. Adsorption of organic molecules from aqueous solutions on carbon materials. Carbon 2004, 42, 83-94. [CrossRef]

44. Park, D.; Yun, Y.-S.; Park, J.M. Studies on hexavalent chromium biosorption by chemically-treated biomass of Ecklonia sp. Chemosphere 2005, 60, 1356-1364. [CrossRef] [PubMed]

45. Park, D.; Yun, Y.-S.; Park, J.M. Mechanisms of the removal of hexavalent chromium by biomaterials or biomaterial-based activated carbons. J. Hazard. Mater. 2006, 137, 1254-1257. [CrossRef] [PubMed]

46. Park, D.; Yun, Y.-S.; Kim, J.Y.; Park, J.M. How to study Cr(VI) biosorption: Use of fermentation waste for detoxifying $\mathrm{Cr}(\mathrm{VI})$ in aqueous solution. Chem. Eng. J. 2008, 136, 173-179. [CrossRef]

47. Choudhary, B.; Paul, D.; Singh, A.; Gupta, T. Removal of hexavalent chromium upon interaction with biochar under acidic conditions: Mechanistic insights and application. Environ. Sci. Pollut. Res. 2017, 24, 16786-16797. [CrossRef] [PubMed]

48. Tran, H.N. Comment on "simultaneous and efficient removal of $\mathrm{Cr}(\mathrm{VI})$ and methyl orange on LDHs decorated porous carbons". Chem. Eng. J. 2019, 359, 810-812. [CrossRef]

49. Tran, H.N.; Pham, V.V.; Vo, D.-V.N.; Nguyen, P.T. Comment on "Removal of hexavalent chromium by biochar supported nZVI composite: Batch and fixed-bed column evaluations, mechanisms, and secondary contamination prevention". Chemosphere 2019. [CrossRef]

50. Liu, R.; Zhu, X.; Chen, B. A New Insight of Graphene oxide-Fe(III) Complex Photochemical Behaviors under Visible Light Irradiation. Sci. Rep. 2017, 7, 40711. [CrossRef]

51. Park, D.; Yun, Y.-S.; Park, J.M. XAS and XPS studies on chromium-binding groups of biomaterial during $\mathrm{Cr}(\mathrm{VI})$ biosorption. J. Colloid Interface Sci. 2008, 317, 54-61. [CrossRef]

52. Rivera-Utrilla, J.; Sánchez-Polo, M. Adsorption of $\mathrm{Cr}(\mathrm{III})$ on ozonised activated carbon. Importance of C $\pi$-cation interactions. Water Res. 2003, 37, 3335-3340. [CrossRef]

53. Arim, A.L.; Quina, M.J.; Gando-Ferreira, L.M. Uptake of trivalent chromium from aqueous solutions by xanthate pine bark: Characterization, batch and column studies. Process. Saf. Environ. Prot. 2019, 121, 374-386. [CrossRef]

(C) 2019 by the authors. Licensee MDPI, Basel, Switzerland. This article is an open access article distributed under the terms and conditions of the Creative Commons Attribution (CC BY) license (http://creativecommons.org/licenses/by/4.0/). 